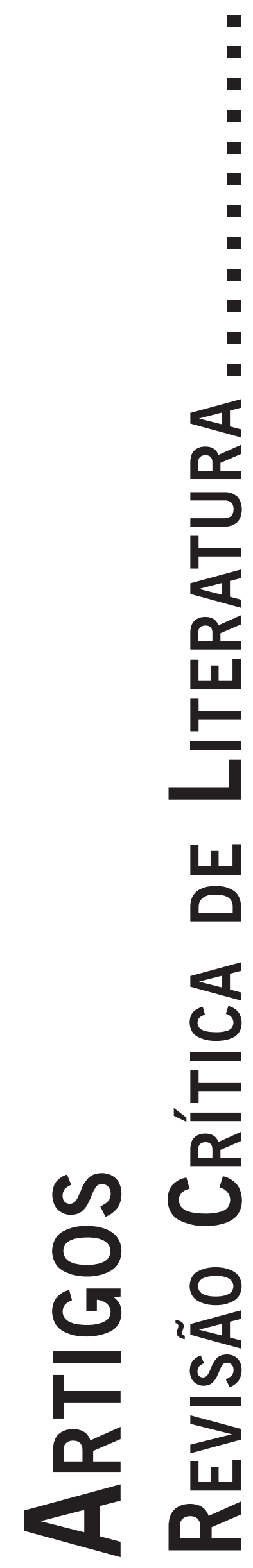




\title{
AJUSTAMENTO CRIATIVO E ESTRESSE NA HIPERTENSÃO ARTERIAL SISTÊMICA
}

\author{
Creative Adjustments and Stress in Hypertension \\ Ajuste Creativo y el Estrés en la Hipertensión
}

Juliana de Oliveira Figueiredo

Emma Elisa Carneiro Castro

\begin{abstract}
Resumo: A hipertensão arterial sistêmica é problema de saúde pública e tem etiologia multifatorial, incluindo fatores psicológicos. Estes fatores interferem na instalação da doença e na forma como o paciente lida com ela. O estresse é apontado como importante fator predisponente da hipertensão, associado a outros fatores de risco, influenciando na reatividade cardiovascular. O objetivo deste trabalho é rever a literatura sobre aspectos psicológicos envolvidos no desencadeamento e na manutenção da hipertensão, destacando o estresse e os conceitos de ajustamento criativo e de mecanismos neuróticos da Gestalt-terapia, apontando a participação dos fatores subjetivos neste processo e a importância do trabalho do psicólogo com pacientes hipertensos. A Gestalt-terapia, enquanto abordagem psicológica organísmica e holística, pode ter importantes contribuições para a compreensão deste fenômeno e no acompanhamento de pacientes hipertensos, favorecendo seus processos de ampliação da awareness, de responsabilização e os ajustamentos criativos.
\end{abstract}

Palavras-chave: Gestalt-terapia; Estresse psicológico; Hipertensão.

\begin{abstract}
Hypertension is a public health problem and has a multifactorial etiology, including psychological factors. These factors influence the onset of the disease and how patients cope with it. Stress is considered an important predisposing factor for hypertension associated with other risk factors, influencing the cardiovascular reactivity. The objective of this paper is to review the literature on psychological aspects involved in the initiation and maintenance of hypertension, highlighting the stress and the concepts of creative adjustment and neurotic mechanisms of Gestalt therapy, pointing the participation of subjective factors in this process and the importance of the psychologists work with hipertensive patients. Gestalt therapy, while organismic and holistic psychological approach may have important contributions to the understanding of this phenomenon and monitoring of hypertensive patients, favoring processes of expansion of awareness, accountability and creative adjustments. Keywords: Gestalt therapy; Psychological stress; Hypertension.
\end{abstract}

Resumen: La hipertensión arterial es un problema de salud pública y tiene una etiología multifactorial, incluyendo factores psicológicos. Estos factores interfieren en la aparición de la enfermedad y em la forma cómo los pacientes lidian con ella. El estrés es apontado como un importante factor predisponente para la hipertensión, asociado a otros factores de riesgo, influyendo en la reactividad cardiovascular. El objetivo de este trabajo es revisar la literatura sobre los aspectos psicológicos implicados en el inicio y mantenimiento de la hipertensión, destacando el estres y los conceptos de ajuste creativo y mecanismos neuróticos de la Terapia Gestalt, senalando la participación de los factores subjetivos en este proceso y la importancia de trabajo psicológico con los pacientes hipertensos. La Terapia Gestalt, mientras que el enfoque psicológico organismico y holístico, puede tener importantes contribuciones a la comprensión de este fenómeno y en el acompanhamento de los pacientes hipertensos, favorecendo los procesos de expansión de la awareness, la responsabilizacion y los ajustes creativos.

Palabras claves: Terapia gestalt; Estrés psicológico; Hipertensión.

\section{Introdução}

Este trabalho tem como objetivo rever os estudos sobre os aspectos psicológicos envolvidos no desencadeamento e na manutenção da hipertensão arterial sistêmica (HAS), em especial, o estresse e os conceitos de ajustamento criativo e mecanismos neuróticos, desenvolvidos pela Gestalt-terapia, apontando a participação dos fatores subjetivos neste processo de adoecimento e a importância do trabalho do psicólogo junto aos pacientes hipertensos.

A HAS é a doença cardiovascular de maior frequência no Brasil, sendo um grave problema de saúde pública nacional e mundial. Tem prevalência de 22,3\% a 43,9\% nos adultos brasileiros, variando de acordo com a cidade na qual os dados foram levantados, tendo incidência de mais de $50 \%$ entre 60 e 69 anos e $75 \%$ acima de 70 anos, conforme apontado pela VI Diretrizes de Hipertensão (Sociedade Brasileira de Cardiologia, Sociedade Brasileira de Hipertensão \& Sociedade Brasileira de Nefrologia, 2010). Esta doença é um fator de risco para outras patologias cardiovasculares, cerebrovasculares e renais, tais como doença cerebrovascular, insuficiência cardíaca, doença arterial coronariana, doença arterial periférica, e doença renal crônica. Por ser assintomática em grande 
parte do seu curso, o diagnóstico, os cuidados necessários e o tratamento podem ser negligenciados pelos portadores, levando a uma baixa taxa de controle (Brasil, 2006).

A VI Diretrizes de Hipertensão (Sociedade Brasileira de Cardiologia et al., 2010, p. 1) define HAS como

(...) uma condição clínica multifatorial caracterizada por níveis elevados e sustentados de pressão arterial (PA). Associa-se frequentemente a alterações funcionais e/ou estruturais dos órgãos-alvo (coração, encéfalo, rins e vasos sanguíneos) e a alterações metabólicas, com consequente aumento do risco de eventos cardiovasculares fatais e não-fatais.

O critério básico que é consenso para o diagnóstico da HAS adotado atualmente considera a pressão arterial sistólica maior ou igual a $140 \mathrm{mmHg}$ e uma pressão arterial diastólica maior ou igual a $90 \mathrm{mmHg}$ nos indivíduos que não estão fazendo uso de medicamentos anti-hipertensivos. Este diagnóstico deve ser realizado com cuidado, de forma a evitar os falsos positivos. Para isto, há a recomendação de que se afira a PA em diferentes períodos nos indivíduos ainda não diagnosticados e que se considere o risco cardiovascular global, que pode ser estimado pela presença de fatores de risco, presença de lesões em órgãos alvo e pelas comorbidades associadas (Brasil, 2006).

Quanto aos fatores de risco, a VI Diretrizes de Hipertensão (Sociedade Brasileira de Cardiologia et al., 2010) aponta idade, sexo, etnia, excesso de peso e obesidade, ingestão de sal, ingestão de álcool, fatores socioeconômicos e genética. Além dos fatores supracitados, encontra-se na literatura que há influência dos aspectos psicológicos no desencadeamento e manutenção da HAS, assim como há a influência de fatores relativos à vulnerabilidade social (Gandarillas, Câmara \& Scarparo, 2005).

MacFaden e Ribeiro (1998) colocam que pessoas submetidas à tensão emocional prolongada apresentam hipertensão frequentemente, relacionando a patologia também à contenção de tendências reprimidas e à presença de ansiedade. Segundo estes autores, a omissão da expressão afetivo-emocional, assim como o bloqueio da ansiedade, podem atuar sobre o sistema nervoso autônomo. Tal fenômeno pode favorecer crises hipertensivas quando há uma disposição genética para a HAS. Inicialmente, essas crises são transitórias, mas podem se tornar permanentes (Lipp, 2010b).

Romano (1999) aponta que os aspectos psicológicos e as intervenções psicológicas empregadas em pacientes hipertensos vão além do que tange ao estresse emocional, interferindo na instalação da doença, nos conhecimentos que o paciente tem sobre ela e os seus fatores de risco, na mudança de hábitos de vida (cessação de tabagismo, alcoolismo, controle de peso) e na adesão ao tratamento. O trabalho deve ser realizado em equipe mul- tiprofissional e considerar o sentido que o paciente dá ao adoecer em sua vida.

O interesse em estudar este tema surgiu a partir do trabalho com pacientes portadores de HAS desenvolvido em ambulatório multiprofissional de hospital público de ensino, específico para atendimento de pacientes hipertensos e com agravos cardiovasculares. Notou-se importante demanda de encaminhamento destes pacientes para atendimento psicológico e, nos pacientes acompanhados pela psicologia, foi percebida a influência de fatores psíquicos em sua relação com a doença, além da manifestação de mecanismos estudados pela Gestaltterapia. A partir do estudo da relação dos estados psicológicos associados à HAS, percebeu-se certa semelhança entre os conceitos de estresse e de ajustamento criativo, que serão explicitados no decorrer deste trabalho. Ajustamento criativo ou ajustamento criador é um conceito próprio da Gestalt-terapia e se refere a uma adaptação (mas não uma adaptação passiva), caracterizando uma interação ativa entre a pessoa e seu meio (Ginger \& Ginger, 1995).

A Gestalt-terapia, enquanto abordagem psicológica de caráter holístico e organísmico, pode ter importantes contribuições na compreensão dos aspectos psicológicos envolvidos no adoecimento, inclusive na HAS, já que toma a existência humana a partir da interação da pessoa com o meio, considerando processos sociais, físicos e psíquicos de cada pessoa. (Perls, Hefferline \& Goodman, 1997; Ginger \& Ginger, 1995).

Ginger e Ginger (1995, p. 17) colocam que "a Gestalt desenvolve uma perspectiva unificadora do ser humano, integrando ao mesmo tempo as dimensões sensoriais, afetivas, intelectuais, sociais e espirituais, permitindo uma experiência global”. A Gestalt-terapia estuda e favorece o contato autêntico consigo e com os outros, os ajustamentos criativos do organismo diante do meio e a consciência dos processos interiores que podem ocasionar condutas repetitivas, considerando as interrupções, as evitações, os medos e as inibições que bloqueiam a pessoa rumo à satisfação de suas necessidades.

\section{Método}

Neste trabalho teórico de revisão narrativa, foram buscados em bases indexadas os descritores Hipertensão, Estresse Psicológico, Gestalt-terapia e seus correspondentes em inglês e em espanhol. Não foram encontrados resultados usando-se estes três descritores simultaneamente na Biblioteca Virtual em Saúde (BVS) e na PsycINFO da American Psychological Association (APA).

Diante da carência de literatura específica sobre o tema suscitado, optou-se por realizar revisão sobre a hipertensão e o estresse psicológico e revisão sobre a Gestalt-terapia e adoecimento para, então, relacionar o conceito de estresse com os postulados da Gestalt-terapia. 
A partir destas revisões, propõe-se uma discussão acerca dos conceitos de ajustamento criativo e de mecanismos neuróticos como fatores psicológicos atuantes no contexto da HAS.

Foram usados os descritores Gestalt-terapia e Hipertensão (1 resultado); Hipertensão e Estresse Psicológico (2438 resultados, sendo 38 na LILACS); Gestalt-terapia e Estresse Psicológico (10 resultados); Psicoterapia e Hipertensão (16 resultados) e Doença e Gestalt-terapia (9 resultados).

Foram utilizados 10 artigos desta busca, tendo como critérios de inclusão artigos em texto completo, articulação de fenômenos psíquicos com desenvolvimento de patologias físicas e relação com a abordagem teórica estudada. Como critério de exclusão, têm-se artigos que enfoquem os aspectos biológicos. Foi realizada ainda busca manual em livros sobre Gestalt-terapia, sobre estresse, nas referências dos artigos encontrados, além de textos lidos previamente à construção deste trabalho.

\section{Estresse e hipertensão}

O estresse é definido por Selye (conforme citado por Moraes, 2010) como uma alteração fisiológica que acontece quando o organismo se encontra em uma situação que exija uma reação mais intensa que sua atividade orgânica normal. O estresse designaria, então, o esforço que é exercido sobre o organismo que excede sua capacidade de adaptação. Esta demanda independe das características do estressor, portanto, é uma demanda não específica.

As observações de Selye neste tema foram iniciadas quando notou que pacientes sofrendo de vários tipos de patologias tinham reações em comum. Essas reações não específicas eram semelhantes e relacionavam-se a situações nas quais estes pacientes passavam por angústia e tristeza. Este conjunto de reações foi designado como síndrome geral de adaptação ou síndrome do estresse biológico. Posteriormente, Selye passou a fazer uso da palavra stress como forma de nomear esta síndrome produzida por vários agentes aversivos (Lipp, 2010a).

Hans Selye propôs um modelo trifásico de estresse, com as fases de alerta, resistência e exaustão. A primeira fase corresponde à preparação para a reação de luta ou fuga, preparando o corpo e a mente para preservação da própria vida diante de situações exigentes ou ameaçadoras. Com a fase de resistência, vem uma tentativa de adaptação, podendo aparecer sensações de desgaste de cansaço. Na terceira fase, com a persistência do estressor e a deficiência de estratégias para lidar com o estresse, o organismo esgota a reserva de energia adaptativa, tendo início o surgimento de doenças sérias (Lipp, 2010a).

A partir do modelo de Selye, Lipp (2010a) propôs um modelo quadrifásico de estresse, introduzindo a fase de quase-exaustão. Ele é composto pelas fases de alerta, resistência, quase-exaustão e exaustão. No modelo quadrifásico de Lipp, o estresse se inicia na fase de alerta, com a percepção de um desafio ou ameaça, havendo um empenho autorregulatório para o qual a pessoa necessita produzir mais força para responder ao que está exigindo dela um maior esforço. Há mobilização fisiológica e psíquica, quebra da homeostase e dispêndio de maior energia para enfrentar a situação em questão. Nesta fase pode ocorrer o aumento da motivação, do entusiasmo e do vigor, podendo levar à maior produtividade. Na fase de resistência, há uma busca pelo reequilíbrio, sendo necessário maior gasto de energia e, consequentemente, maior desgaste orgânico, sendo comum a sensação de fadiga sem causa aparente, além de outras consequências.

Quando ocorre uma adaptação adequada diante da situação estressora, o processo de estresse é interrompido sem consequências importantes. Se há continuação deste processo, o organismo entra na fase de quase exaustão, quando há um enfraquecimento da pessoa e diminuição das resistências às tensões, de forma que o organismo não consegue o restabelecimento da homeostase. Nesta fase, é comum a alternância de momentos de bem-estar com momentos de desconforto e cansaço. Doenças surgem, mostrando que a resistência perdeu sua eficácia. Há um desgaste significativo e a presença de diversos sintomas, mas a pessoa ainda é capaz de se manter socialmente ativa (Lipp, Cabral \& Grun, 2009). A fase de exaustão tem características semelhantes às da fase anterior, porém com maior magnitude, levando ao esgotamento físico e psíquico, que pode se manifestar como exaustão física e depressão. A pessoa para de funcionar adequadamente, chegando a não conseguir trabalhar ou se concentrar.

O estresse é um fator de importante interferência na qualidade de vida, sendo relacionado ao desenvolvimento de diversas patologias. Uma pessoa estressada pode sentir-se mal consigo, ser pouco produtiva, ter dificuldades de relacionamento e falta de motivação, correndo risco de adoecer. Lipp et al. (2009) mencionam gastrite, problemas dermatológicos, ansiedade, depressão e variações de PA como distúrbios associados a altos níveis de estresse.

Santos, Santos, Melo e Alves Júnior (2006) falam do estresse como um processo de caráter complexo e multidimensional, no qual estressores agudos ou crônicos têm ação, o que leva à excitação emocional. Ao perturbarem a homeostase, estes estressores disparam um processo de adaptação que produz diversas reações sistêmicas, podendo ocasionar distúrbios psicológicos e fisiológicos. Lipp (2010a) o descreve como um processo, uma reação psicofisiológica complexa que se origina na necessidade de o organismo responder a algo que ameace a homeostase, podendo ser situações negativas como confrontos, dor, fome ou mesmo a situações que façam o indivíduo muito feliz. 
Segundo Lipp (2010a), o estresse excessivo e prolongado produz cansaço mental, apatia, crises de ansiedade, afeta o sistema imunológico e pode desencadear doenças latentes, como a HAS. Pesquisas envolvendo reatividade cardiovascular (Lipp, 2001, 2007, 2010b; Lipp, Frare \& Santos, 2007) mostram que sujeitos hipertensos submetidos a sessões experimentais de estresse emocional apresentam aumento de PA significativo e que variáveis como inassertividade ou alexitimia (dificuldades em identificar e expressar emoções) são determinantes da reatividade cardiovascular.

Reatividade cardiovascular refere-se às mudanças na PA e/ou na frequência cardíaca ocasionadas pela resposta do organismo a alguma situação ou evento específico (Lipp et al., 2007). Ela é estimulada por determinadas situações e pode ser um alerta para o desenvolvimento do autocuidado, muitas vezes negligenciado pelo hipertenso (Brasil, 2006). Este cuidado deve ser realizado a longo prazo, no entanto, aumentos súbitos dos níveis de PA podem atingir níveis que exijam cuidados imediatos. Sobre a reatividade cardiovascular, convém ressaltar que tem sido considerada importante na neurogenética de neoplasias, de doenças coronárias e da aterosclerose (Lipp, 2007).

Em estudo realizado em 2007, Lipp et al. verificaram maior magnitude dos aumentos pressóricos nos momentos nos quais o hipertenso foi levado a expressar seus sentimentos de modo direto, concluindo-se que as situações desafiadoras ou estressantes podem ter um efeito estressor que varia de acordo com o nível de controle que os pacientes exercem sobre suas emoções. Verificou-se que a PA não variava uniformemente, mas que aumentos significativos na pressão arterial diastólica ocorriam principalmente nas condições em que a pessoa era solicitada a expressar suas emoções de modo livre. No que se refere à pressão arterial sistólica, a reatividade foi maior nas situações em que era solicitado ao participante que não expressasse seus sentimentos durante períodos de estresse. Outra observação deste estudo refere-se ao fato de que as pessoas inassertivas ou alexitímicas apresentaram maior reatividade na pressão arterial diastólica quando solicitadas a expressarem seus sentimentos e maior reatividade na pressão arterial sistólica quando levadas a regular ou restringir a expressão de emoção.

Lipp et al. (2009) apontam o estresse produzido pela raiva com um dos fatores capazes de produzir reatividade cardiovascular excessiva. A raiva pode acarretar problemas no campo social/relacional e também na saúde, sendo fator de risco para depressão, doença coronariana, úlceras, morte prematura e suicídio (Lipp, conforme citado por Lipp et al., 2009). A raiva é um estado emocional que se relaciona à estimulação do sistema nervoso autônomo, ocorrendo quando uma pessoa sente-se ameaçada, injustiçada ou frustrada, tendo uma função de proteção (Spielberger \& Biaggio, conforme citado por Lipp et al., 2009). Estudos atentam para o fato de que emoções como raiva e hostilidade, quando bloqueadas ou não expressas, podem favorecer crises hipertensivas através da ativação crônica do sistema nervoso simpático, especialmente quando há outros fatores de risco atrelados (Fonseca, Coelho, Nicolato, Malloy-Diniz, \& Silva Filho, 2009; Alexander, conforme citado por Rosa, 2008; MacFaden \& Ribeiro,1998).

Rosa (2008) cita os estudos de Franz Alexander, Campos e de Lipp, que traçam um perfil do hipertenso, caracterizando-o como alguém hostil, mas com pouca ou nenhuma expressão desta hostilidade, tendo contato limitado com seus próprios sentimentos e sensações físicas, intenso desejo de manter controle sobre seus sentimentos e sobre o ambiente e dificuldades em interações sociais. Além destes aspectos, são referidas características como alexitimia, depressão, passividade e expectativas negativas diante das situações. Tais aspectos não justificam a HAS, mas apontam para um núcleo de tensão mantenedor de elevados níveis de PA.

Considerando a hipertensão sob a ótica da psicossomática, Rosa (2008) focaliza o exposto pela Escola de Chicago e pela Escola Psicossomática de Paris. A primeira enfatiza que conflitos inconscientes poderiam ocasionar tensões emocionais que, a partir de uma cronicidade, teriam correlatos fisiológicos, resultando em disfunções. Esta escola caracteriza o hipertenso como alguém que tem conflitos envolvendo seus desejos de passividade e dependência, controle, domínio e autonomia. No que tange à personalidade, há a oposição entre o desejo de agradar e o de ser aprovado pelas figuras de autoridade e uma postura rebelde ou agressiva. A Escola Psicossomática de Paris coloca o sintoma psicossomático como uma possibilidade de reorganização estabelecida no movimento de adaptação da pessoa a estímulos internos ou externos, sendo que o sintoma surge quando a pessoa ultrapassa um limiar de conflito ou sofrimento.

\section{Gestalt-terapia, saúde e doença}

A Gestalt-terapia é uma abordagem psicológica de base organísmica que toma a existência humana a partir de um conceito holístico, que considera o processo relacional. Propõe como tarefa fundamental da psicologia "estudar a operação da fronteira de contato no campo organismo/ ambiente" (Perls et al., 1997, p. 43). Esses autores (p. 45) colocam que "todo contato é ajustamento criativo do organismo e ambiente" e que "a psicologia é o estudo dos ajustamentos criativos".

Na concepção de Polster e Polster (2001), o contato é a função que sintetiza a necessidade de união e separação, ou seja, corresponde ao encontro da pessoa com o mundo externo de modo nutridor e é através dele que a percepção de uma pessoa sobre a sua identidade pode se desenvolver plenamente. É também a partir do contato, e calcado na relação entre o indivíduo e a alterida- 
de, que a pessoa pode se ajustar criativamente ao seu meio, estabelecendo condições para seu crescimento e bem estar. Todo ato contatante é awareness, resposta motora e sentimento, sendo, portanto uma cooperação dos sistemas da pessoa - sensorial, muscular e vegetativo (Perls et al., 1997).

Yontef (1998, p. 31) define awareness como

(...) o processo de estar em contato vigilante com os eventos mais importantes do campo indivíduo/ ambiente, com total apoio sensoriomotor, emocional, cognitivo e energético. O insight, uma forma de awareness, é uma percepção óbvia e imediata de uma unidade de elementos, que no campo aparentam ser díspares. O contato com awareness gera totalidades significativas novas e, portanto, é em si a integração de um problema.

Quando eficaz, é baseada e energizada pela necessidade dominante presente do organismo, o que requer autoconhecimento e conhecimento da situação atual. Quando se negam as exigências da situação ou quando se nega o que é pertinente à pessoa, ocorre uma perturbação da awareness. A awareness é acompanhada por um processo de conhecimento do controle, da escolha e da responsabilidade da pessoa sobre o que sente, o que faz e como faz. Acontece sempre no aqui-e-agora, sendo, portanto, um processo dinâmico. A ausência de awareness é resultado do não estabelecimento de contato pleno entre o organismo e o meio, seja devido ao fato de a pessoa estar imersa em seu próprio meio interno, seja pela falta de contato com sua vida interior pela fixação com o que é externo. A awareness, portanto, relaciona-se com o movimento de mudança espontânea e com os ajustamentos criativos (Yontef, 1998).

Ajustamento criativo é uma interação organismo/ meio no qual a pessoa tem contato, reconhece e lida com seu contexto de vida e "assume a responsabilidade pela criação das condições que conduzirão ao seu próprio bem-estar" (Yontef, 1998, p. 227). Anthony (2009) explica que o ajustamento criativo é um processo dinâmico e ativo no qual há um engajamento do indivíduo com o ambiente na busca da resolução de situações e restauração do equilíbrio e da saúde do organismo, ocorrendo por meio da autorregulação organísmica. A autora, citando Frazão, coloca que este ajustamento é necessário em dado momento, mas na medida em que há a manutenção de comportamentos provocados por este ajuste de forma cristalizada, ele pode constituir um ajustamento disfuncional.

Na autorregulação organísmica, a escolha e os aprendizados se dão de forma holística, havendo a integração natural entre corpo e mente, entre o que se pensa e o que se sente, entre o que é espontâneo e o que é deliberado (Yontef, 1998). Perls et al. (1997) apontam que mesmo em situações objetivamente imutáveis, emergem reações re- gulatórias do organismo, como o choro e o luto, que contribuem para a restauração do equilíbrio, se a pessoa permite a expressão destas reações.

Ginger e Ginger (1995) afirmam que as expressões corporais e emocionais são censuradas e filtradas de forma bastante estrita em nossa cultura. "Proibiram-nos desde a infância de manifestar abertamente a raiva, o medo, a tristeza, a dor, o ciúme... Proibiram-nos também de gritar nossa alegria ou de expor nosso desejo...” (p. 163). Lembram que a palavra emoção tem origem no latim emovere, de ex-movere, que significa mover para fora e que a inibição da emoção e a inibição da ação podem alimentar neuroses, psicoses, doenças psicossomáticas e conturbações sociais.

Tratando da inibição da ação, estes autores explicam que interrupções prolongadas e repetidas de uma ação em curso podem levar a consequências patológicas. Falase de um sistema de inibição da ação, que é acionado nos momentos em que as reações normais de defesa do organismo (fuga ou luta) não são possíveis ou são inoportunas. Este sistema de inibição é destinado a funcionar apenas por períodos curtos. Caso funcione por um período muito longo, pode levar a uma desregulação dos neuromediadores, acarretando perturbações, como úlceras e hipertensão. Recorrendo aos estudos do biólogo Henri Laborit, Ginger e Ginger (1995), afirmam que a inibição da ação é base de doenças e que comportamentos interrompidos ou proibidos são bastante comuns em nossa sociedade, resultando em pessoas que não conseguem exprimir suas necessidades, seus desejos e sua raiva.

Perls et al. (1997) trazem o exemplo de uma pessoa em que todas as vezes em que se emociona a ponto de começar a chorar, não se sente com vontade de chorar, e não chora. Explica-se que isto acontece, pois a referida pessoa já se acostumou a não perceber como está inibindo muscularmente a função do choro e impedindo a manifestação dele. Neste caso, aparecem repercussões físicas, como dores de cabeça e falta de fôlego. O corpo é imobilizado para impedir a expressão da awareness do choro. Muitas vezes, apenas quando essa pessoa fica doente é que se dá conta do seu corpo e de suas necessidades.

Quando o contato se estabelece de forma efetiva, alterna-se entre união e separação e entre estar em contato com o ambiente atual e o afastamento da atenção do ambiente (Yontef, 1998). Existem, contudo, distúrbios de contato ou de awareness que correspondem aos mecanismos neuróticos que interrompem algum ponto do ciclo de contato ou reduzem sua capacidade, limitando a pessoa e impedindo a autorregulação do organismo. Através deles, a energia é direcionada para outros sentidos, sendo desviada de forma resistente. São eles a introjeção, a projeção, a retroflexão, a deflexão e a confluência (Polster \& Polster, 2001).

A introjeção corresponde à incorporação passiva do que é proporcionado pelo ambiente, fazendo pouco ou nenhum esforço para especificar a própria exigência ou 
preferência, usando a energia para manter-se satisfeito com as coisas conforme elas são encontradas. A projeção é a atribuição de aspectos que são próprios da pessoa a outros ou ao ambiente, podendo revelar a não aceitação de sentimentos ou ações por a pessoa acreditar que não deveria senti-los ou tê-los, ligando o que é perturbador a outra pessoa ou objeto. Nesta forma de interrupção, há uma abdicação da própria participação na direção da energia, experienciando a impotência na realização de mudanças.

A retroflexão é um mecanismo no qual se restringe a troca de energia com o meio, investindo-a em si e abandonando as possibilidades de modificação do ambiente. Ocorre um confronto crônico entre energias mutualmente contrárias dentro do indivíduo. Assim, a pessoa fica estagnada e contida e não se move para a ação necessária. A deflexão corresponde a uma evitação de contato direto, não direcionando energia pra um alvo específico. Não há investimento de energia para obter um retorno satisfatório, o que ocasiona um esgotamento. Defletindo, o indivíduo pode extrair pouco do que faz ou sentir-se imóvel, entediado, confuso, vazio, deslocado e desimportante. A confluência é um mecanismo no qual o indivíduo mistura-se a outros ou ao ambiente, vivendo de forma indiferenciada, o que leva a pouco gasto de energia, mas pouca clareza da direção que se quer seguir.

Todos estes mecanismos significam uma interrupção em algum ponto do ciclo de contato. No entanto, faz-se necessário enfatizar que estes mecanismos de evitação de contato não são necessariamente patológicos, podendo ser saudáveis conforme sua intensidade, sua maleabilidade e o momento no qual eles emergem (Ginger \& Ginger, 1995). Perls et al. (1997) falam de uma sabedoria organísmica, que se refere ao uso dessas resistências pelo self em situações de restrição de contato ou de potencial ameaça. Portanto, estes mecanismos têm função preservativa e podem ser estratégias criativas e saudáveis de proteção.

Quando se fala em patologias de ordem psicossomática, esses mecanismos neuróticos podem ter papel importante em seu desencadeamento. Destaca-se a retroflexão na gênese dos adoecimentos físicos para os quais o indivíduo já possui outros fatores de risco agregados. Yontef (1998) explicita que este é um mecanismo que conduz ao isolamento e cita a ideação de autossuficiência como um exemplo, pois aí o indivíduo substitui o self pelo ambiente. Alvim, Bomben e Carvalho (2010) falam deste mecanismo como uma interrupção do fluxo de energia no momento em que já se mobilizou esta energia para a ação, antes orientada para o ambiente:

A pessoa interromperia a ação pelo medo da agressão necessária para a transformação e assimilação da diferença. Sua sensação diante de um iminente conflito é de que haverá destruição, desintegração, algum tipo de desastre, e assim ela volta as energias - já compro- metidas - contra si própria, o único objeto "seguro" disponível no campo. (Alvim et al., 2010, p. 184)

Quando a atividade é redirigida para dentro, a pessoa coloca-se no lugar do meio e se torna agente e paciente da ação. Não há um enfrentamento da situação, pois a pessoa tem medo de ferir e ser ferido, destruir e ser destruído. Assim, há um abandono da espontaneidade e da agressividade natural que é fundamental para a assimilação de novidade devido à introjetos que levam à repressão da agressividade (Alvim et al., 2010). O processo de ajustamento criativo envolve sempre as fases de agressão e destruição, pois é apoderando-se de antigas estruturas e alterando-as que o estado anterior do que é contatado é destruído no interesse de um novo contato. Este processo pode provocar medo, interrupção e ansiedade proporcionais à inflexibilidade e à falta de fluidez do self (Perls et al., 1997).

Na perspectiva gestáltica, a saúde e a doença são conceitos dinâmicos, não polarizados, caracterizados pela interação, sendo formas do organismo dar sentido à sua existência na busca de trocas constantes com o meio. Saúde não é a ausência de doença. Assim, o desaparecimento dos sintomas não significa necessariamente 0 retorno ao estado saudável. O não saudável é a impossibilidade encontrada pelo organismo de atualizar-se, permanecendo estagnado, com respostas disfuncionais (Fukumitsu, Cavalcante \& Borges, 2009).

A pessoa tende a se autorregular de forma a se relacionar melhor consigo e com o meio circundante, tende a utilizar sua energia criativa na busca do equilíbrio a partir do que é exigido por si mesmo e pelo meio, resultando em um ajustamento criativo. Este ajustamento criativo pode dar mais ênfase ao criativo que ao adaptativo, causando certo estranhamento a princípio por não ser a melhor solução aparente. No entanto, deve ser lembrado que ele se dá de acordo com os recursos que a pessoa encontra no momento para lidar com a situação (Nunes \& Holanda, 2008).

O adoecer é uma forma de autorregulação que mostra a pessoa fazendo uso dos seus recursos para enfrentar sofrimentos e tensões. Os sintomas, como gestos, pensamentos e tensões corporais apareceriam como tentativas de ajustamentos criativos. A doença relaciona-se com a interrupção da capacidade de dar respostas criativas a específicas situações conflitivas e às suas necessidades internas (Anthony, 2009).

A doença pode ser uma forma física de expressar experiências vividas por uma pessoa. Em uma perspectiva holística, a doença se relaciona com o físico/fisiológico, com as atividades que interferem no corpo, com o contexto relacional e com as atitudes da pessoa consigo e com o contexto no qual ela está inserida (Silva \& Boaventura, 2011). Neste sentido, o corpo e suas manifestações são espaços para a expressão subjetiva e para a atribuição de novos sentidos. Saúde e doença não são 
polos indissociáveis ou autoexcludentes, mas partes de um processo dinâmico e contínuo (Freitas, Stroiek \& Botin, 2010).

Silva e Boaventura (2011) colocam ainda que se o organismo não alcança a satisfação por meio da homeostase, seja no âmbito fisiológico ou psicológico, ele adoece, mostrando uma forma de dizer que há algo errado, um ajustamento criativo. No entanto, nem sempre estes processos de ajustamento levam a crescimentos saudáveis. Podem ser a melhor resposta que a pessoa encontra para lidar com determinadas situações mas, se cristalizadas, podem ser limitantes.

Ainda segundo estas autoras, citando Brandão, a doença é um momento de crise, mas pode ser concebida como uma oportunidade de mudança, de percepção de novas formas de se expressar no mundo e exige a participação do indivíduo. Esta participação pode se dar por meio de comportamentos físicos, emocionais ou mentais, como negligência aos cuidados prescritos, manutenção do estresse, preocupação em atender aos outros, descuidando das próprias necessidades e limitando suas satisfações. A pessoa pode lidar com as diversas facetas do adoecer, tendo neste contato uma forma de experimentar este processo e explorar os bloqueios e cristalizações que interferem no contato e na relação organismo/meio.

A concepção gestáltica de saúde refere-se ao comportamento livre, espontâneo, criativo e fluido. Além da doença ou dos sintomas, têm-se suas expressões verbais, físicas e o sentido que a pessoa atribui às suas vivências, sendo necessário ultrapassar o sintoma e considerar a pessoa em sua totalidade para que seja possível trabalhar seus processos terapeuticamente (Nunes \& Holanda, 2008).

Um processo saudável apresenta-se como uma forma fluida segundo a qual a pessoa se coloca no mundo e relaciona-se com a consciência e a maneira como vivencia e reconhece suas singularidades. Saudável é estar aberto às modificações e disposto para a instituição de novas formas de saúde, abandonando uma postura passiva de total obediência às normas (Fukumitsu et al., 2009). Estes autores apontam ainda que é necessário que o profissional de saúde não fixe sua atenção nos conceitos de saúde ou de doença, exclusivamente, mas que observe a forma como a pessoa percebe suas vivências e compreende sua experiência de adoecer.

A Gestalt-terapia traz que cada nova situação exige da pessoa novas respostas e atualizações, portanto, a doença, que é uma crise, é situação que demanda uma reorganização. Um corpo desorganizado pode expressar um psiquismo desorganizado. O Gestalt-terapeuta, apoiado na crença nas potencialidades do ser humano e considerando o ser como passível de ser criativo e flexível, pode buscar juntamente com a pessoa novas formas de desenvolver suas potencialidades e ampliar sua responsabilidade individual (Fukumitsu et al., 2009).
Segundo Silva e Boaventura (2011), com a integração da atenção e da tomada de consciência, a pessoa pode mobilizar seus recursos de enfrentamento diante de uma doença. Este contato real com a necessidade que emerge possibilita o surgimento de novas percepções e novos significados. Assim, a pessoa vai se apropriando de si, sendo ativa dentro de seus processos e ressignificando a doença.

\section{Considerações finais}

A literatura aponta para fatores psicológicos influenciando o desencadeamento da HAS e a forma como o hipertenso lida com ela. Foram encontrados muitos estudos tratando do estresse e sua relação com a HAS, mas não foi encontrada literatura sobre esta forma de adoecimento e a Gestalt-terapia. No entanto, os estudos sobre estresse se aproximam de diversas formas ao que é postulado por esta abordagem psicológica.

Tanto os teóricos da Gestalt-terapia quanto os estudiosos do estresse falam da forma como a pessoa se coloca no mundo como processo de ordem multidimensional, impetrado por meio da autorregulação organísmica. Ainda, o intento do organismo nestes dois paradigmas é ir em direção ao estado de equilíbrio ou homeostase. Tanto o estresse como os ajustamentos criativos levam em consideração o que é exigido pelo meio e as exigências da própria pessoa diante de situações que se configuram como estressoras. Ambos consideram as perspectivas relacional, fisiológica e psicológica.

O estresse é colocado como uma reação adaptativa do organismo diante de um evento que exija uma resposta que vá além do que é habitual. Trata-se de uma resposta de caráter processual e fásica, que visa à adaptação do organismo. A princípio, é uma resposta esperada e que pode até levar à mobilização e ao uso de energia para que a pessoa seja mais produtiva e lide de forma positiva com as situações. Entretanto, o estresse passa ser um ponto problemático quando traz prejuízos à qualidade de vida com a persistência do estressor e a incapacidade de estabelecer condutas resolutivas para a questão ou de perceber outras formas de se relacionar com ela.

O ajustamento criativo também é concernente a um processo adaptativo do organismo. É realizado através da autorregulação organísmica e de um potencial criador inerente ao ser humano e relaciona-se à awareness e ao insight emergente diante do que é vivido. Este insight permite reconhecer cada momento em suas especificidades e singularidades, ponderar e escolher dentro das possibilidades disponíveis como responder e se responsabilizar pelas vivências. Esta resposta aware e abrangente corresponde ao ser se ajustando criativamente. Quando se tem condutas repetitivas, usando este ajustamento que ora foi fluido e funcional de forma estereotipada e enrijecida, o ciclo de contato é interrompido. A pessoa 
assume uma postura mais generalista e passiva, ocasião na qual se percebe a ação negativa dos mecanismos que bloqueiam a awareness.

Pode-se falar da presença de mecanismos de interrupção do contato em pacientes hipertensos. Esses mecanismos podem interromper o fluxo de energia em qualquer ponto do ciclo de satisfação de necessidades. Como apontado, o hipertenso tende a não expressar suas necessidades, desejos e sentimentos. Ao invés de se apoiar no meio, canaliza sua energia para si mesmo por medo de criar conflitos em suas relações interpessoais, o que é característico da retroflexão. Assim, é comum que ocorra a manifestação de crises hipertensivas após situações estressoras, como conflitos familiares ou pressões no ambiente de trabalho, nas quais a pessoa não expressa seus sentimentos e suas necessidades. Quando se opta por esta omissão, a energia que deveria ser direcionada para o meio é investida na própria pessoa, gerando estresse no organismo e podendo ocasionar crises hipertensivas devido à reatividade cardiovascular. Se essa forma de ser no mundo se cristaliza, pode haver recorrência dessas crises e instalação da HAS quando há outros fatores de risco associados.

Considerando o perfil traçado do hipertenso nos estudos sobre estresse, percebe-se que é comum que a pessoa se cale diante de uma injustiça ou de algo que a incomode ou a provoque por receio de magoar a terceiros ou mesmo de se expor. Assim, se pode falar da ação dos mecanismos neuróticos que interrompem o contato e a awareness. Essa foi a forma que a pessoa encontrou para lidar com o que lhe demandava um posicionamento. E esta é uma forma que pode ser útil e funcional em diversos contextos, mas não em todos. Por isso, faz-se necessário perceber e escolher, discriminando o posicionamento ou a ação adotados a diante de cada situação.

Quando o organismo está sob a ação destes mecanismos, ele fica estressado e sobrecarregado, tentando buscar constantemente formas de se ajustar ao contexto vivido. Se essas tentativas não encontram eficácia, as gestalten não são fechadas e a satisfação não é alcançada. Com as gestalten inacabadas e a partir dos modelos de estresse, considera-se que há o avanço para as fases finais, de quase exaustão e de exaustão, havendo importante desgaste do organismo. Assim, tem-se que uma pessoa interrompe o contato nutridor com o meio quando, por diversos motivos, não encontra a resolubilidade para as suas questões afetivas, emocionais, sociais, familiares ou não consegue se colocar diante desses atravessamentos, ficando restrita a si. Estando restrita e carecendo do contato nutridor, a pessoa pode manifestar isso em seu corpo, ainda que não haja intenção neste fenômeno.

O estresse é tido como fator que favorece o aparecimento de doenças como úlceras, hipertensão, dermatites, transtornos de ansiedade e transtornos depressivos. As reações sistêmicas ao estresse podem ocasionar distúr- bios fisiológicos ou psicológicos, podendo levar a certo esgotamento mental, apatia, baixa imunidade. Produz ainda cansaço mental, apatia, crises de ansiedade, afeta o sistema imunológico e pode desencadear doenças latentes, como a HAS. A manutenção do estresse pode ser ligada a uma deficiência na awareness. Uma pessoa que não está aware de si e de seu meio tem restrições quanto a perceber possibilidades de resolução do fator estressor ou de formas de se se adaptar a ele.

A HAS pode ser uma consequência de um ajustamento criativo anterior que se cristalizou, perdendo sua função. Diante das pressões impostas pelo contexto no qual a pessoa está inserida e até das pressões autodirigidas resultantes de introjetos, pode acontecer o redirecionamento de sua energia para outros alvos que não a satisfação das suas necessidades. Em determinadas ocasiões, introjetar, projetar, retrofletir, defletir ou confluir podem ser a melhor resposta encontrada pela pessoa, mas é necessário que sejam vislumbradas outras possibilidades para que as gestalten não permaneçam abertas e o ciclo de satisfação das necessidades seja fechado.

O hipertenso muitas vezes negligencia o cuidado com sua saúde. Um fator apontado refere-se ao fato de ser uma doença assintomática em parte do seu curso. Quando há negligência neste cuidado mesmo após o diagnóstico e o aparecimento dos sintomas, pode ser considerada a possibilidade de esta ser uma forma da pessoa perceber o que é ter hipertensão e entrar em contato com o que lhe é interno. A permanência desta postura por longo prazo é disfuncional, mas se não for uma postura rígida, pode ser parte do movimento desta adaptação ativa, parte do processo de apropriação de si e de ressignificação do adoecer. Só quando se tem consciência de si é possível ajustar-se criativamente.

O organismo media suas próprias necessidades e o que transcende a ele. Mas se for considerada apenas uma ou outra necessidade de forma isolada, o contato fica interrompido por muito tempo, podendo ocasionar disfunções de ordem psíquica ou fisiológica. O aumento de PA está elencado como uma reação possível neste contexto. Foi experimentalmente demonstrado que em situações de estresse, variáveis como inassertividade e alexitimia influenciam a reatividade cardiovascular e no aumento da PA. A repressão ou omissão de pensamentos e sentimentos originadas no sistema de inibição pode favorecer crises hipertensivas através da ativação crônica do sistema nervoso simpático. Chega a ser traçado um perfil do hipertenso, que se trata de uma pessoa que não consegue expressar sua hostilidade e busca controlar seus sentimentos e seu ambiente, retrofletindo ou direcionando a energia de maneiras com as quais não se obtém um contato nutridor.

Com a inibição contínua dos sentimentos, das emoções e das ações, podem surgir doenças de ordem psicológica ou psicossomática que repercutem na pessoa, em 
suas interações e em seu ambiente. Podem ser omitidas reações naturais de luta ou fuga ou comportamentos tidos como inoportunos, o que tem um valor de ajustamento desde que realizado de forma ativa. No entanto, se o sistema de inibição permanece constantemente ativado pode levar a interferências na modulação fisiológica dos sistemas ligados ao estresse, dando lugar ao aparecimento de doenças.

O modelo quadrifásico de estresse de Lipp (2010a) propõe em sua primeira etapa, a fase de alerta, que neste momento há mobilização fisiológica e psíquica, com quebra da homeostase. A pessoa já está em estado de estresse, mas há nesta fase a possibilidade de aumento da motivação, do entusiasmo e da energia. Na fase de resistência, ocorre a busca pelo reequilíbrio. É passando por estas fases que surgem os ajustamentos criativos. O organismo discrimina a sua demanda e a demanda do ambiente, entrevê as possibilidades e faz uso das suas potencialidades para se adaptar. São fechadas gestalten e abertas novas necessidades a serem satisfeitas. As fases de quase exaustão e exaustão podem ser comparadas aos ajustamentos disfuncionais, quando há um enfraquecimento da pessoa e dificuldades em reestabelecer o equilíbrio e com importantes perdas funcionais. As estratégias que a pessoa consegue vislumbrar para lidar com as situações estressoras ficam restritas, ou os ajustamentos se cristalizam, não sendo satisfeitas as necessidades.

Faz-se importante ressaltar que a Gestalt-terapia tem uma visão integrada do ser, portanto, quando se fala de saúde e de doença, se fala do todo. A ênfase não está no fato de ser um adoecimento físico ou psicológico, pois se sabe que ambos os aspectos, corpo e psiquismo, carecem de equilíbrio por serem mutualmente influenciados, constituindo algo único, integrado. Quando se fala de qualquer aspecto relativo a uma pessoa, considera-se tudo que está envolvido na relação desta pessoa consigo e com a alteridade. Então, a saúde ou a doença se relacionam ao ser integrado.

O trabalho do psicólogo a partir da abordagem gestáltica tem como foco a responsabilização e a awareness. A pessoa consciente de si e do sentido do adoecer em sua vida tem mais condições de assumir ativamente seu tratamento, estando hábil a responder por ele e por outras dimensões de sua vida. Uma pessoa aware pode ter uma percepção ampliada de suas possibilidades e desenvolver melhor suas potencialidades, mesmo diante de situações de crise ou desafiadoras. A HAS é uma doença crônica, que exige da pessoa vários cuidados e várias modificações, o que pode ser um desafio. Compete ao psicólogo auxiliar a pessoa a se perceber e se implicar em seus processos de vida, incluindo os processos de saúde e doença, propiciando posturas mais espontâneas que consideram o self e o que transcende a ele, resultando na autoatualização e no bem estar do paciente.

\section{Referências}

Alvim, M. B., Bomben, E., \& Carvalho, N. (2010). "Pode deixar que eu resolvo!” - Retroflexão e contemporaneidade. Revista da Abordagem Gestáltica, 16(2), 183-188.

Anthony, S. M. R. (2009). A criança com transtorno de ansiedade: seus ajustamentos criativos defensivos. Revista da Abordagem Gestáltica, 15(1), 55-61.

Brasil. Ministério da Saúde. (2006). Secretaria de Atenção à Saúde. Departamento de Atenção Básica. Hipertensão arterial sistêmica para o Sistema Único de Saúde/Ministério da Saúde, Secretaria de Atenção à Saúde, Departamento de Atenção Básica. Caderno de Atenção Básica, n. 15. Brasília: Ministério da Saúde.

Fonseca, F. C. A., Coelho, R. Z., Nicolato, R., Malloy-Diniz, L. F., \& Silva Filho, H. C. (2009). A influência de fatores emocionais sobre a hipertensão arterial. J Bras Psiquiatria, 58(2), 128-134.

Freitas, J. L., Stroiek, N. N., \& Botin, D. (2010). Gestalt-terapia e o diálogo psicológico no hospital: uma reflexão. Revista da Abordagem Gestáltica, 16(2), 141-147.

Fukumitsu, K. O., Cavalcante. F., \& Borges, M. (2009). O cuidado na saúde e na doença: uma perspectiva gestáltica. Estudos e Pesquisas em Psicologia, 9(1), 172-182.

Gandarillas, M. A., Câmara, S. G., \& Scarparo, H. (2005). Estressores sociais da hipertensão em comunidades carentes. Psicologia: Reflexão e Crítica, 18(1), 62-71.

Ginger, S., \& Ginger, A. (1995). Gestalt - Uma terapia do contato. São Paulo: Summus.

Lipp, M. E. N. (2001). O treino psicológico de controle do estresse como prática clínica para a redução da reatividade cardiovascular de hipertensos. Temas em psicologia da SBP, 9(2), 91-98.

Lipp, M. E. N. (2007). Controle do estresse e hipertensão arterial sistêmica. Revista brasileira de hipertensão, 14(2), 89-93.

Lipp, M. E. N. (2010a). O modelo quadrifásico do stress. Em M. N. E. Lipp (Org.), Mecanismos neuropsicofisiológicos do stress: teoria e aplicações clínicas (p. 17-21). São Paulo: Casa do Psicólogo.

Lipp, M. E. N. (2010b). Reatividade Cardiovascular: Efeitos diferenciais de expressar ou inibir emoções durante momentos de stress emocional. Em M. N. E. Lipp (Org.), Mecanismos neuropsicofisiológicos do stress: teoria e aplicações clínicas (p. 37-41). São Paulo: Casa do Psicólogo.

Lipp, M. E. N., Cabral, A. C., \& Grun, T. B. (2009). Estudo de caso: treino cognitivo de controle da raiva em paciente com hipertensão leve. Revista Brasileira de Terapia Comportamental e Cognitiva, 11(2), 231-245.

Lipp, M. E. N., Frare, A., \& Santos, F. U. (2007). Efeitos de variáveis psicológicas na reatividade cardiovascular em momentos de stress emocional. Estudos de Psicologia, 24(2), 161-167.

MacFaden, M. A. J., \& Ribeiro, A. V. (1998). Aspectos psicológicos e hipertensão essencial. Rev. Assoc. Med. Bras., 44(1), 4-10. 
Moraes, A. B. A. (2010). O stress e as doenças bucais. Em M. N. E. Lipp (Org.), Mecanismos neuropsicofisiológicos do stress: teoria e aplicações clínicas (p. 115-120). São Paulo: Casa do Psicólogo.

Nunes, A. L., \& Holanda, A. (2008). Compreendendo os transtornos alimentares pelos caminhos da Gestalt-terapia. Revista da Abordagem Gestáltica, 14(2), 172-181.

Perls, F., Hefferline, R., \& Goodman, P. (1997). Gestalt-terapia. São Paulo: Summus.

Polster, E., \& Polster, M. (2001). Gestalt-terapia integrada. São Paulo: Summus.

Romano, B. W. (1999). Aspectos psicológicos do paciente coronariopata portador de hipertensão arterial. Revista brasileira de hipertensão, 6(1), 57-9.

Rosa, D. P. (2008). Um olhar psicológico para o hipertenso. Em C. P. Almeida, \& A. L. A. Ribeiro (Orgs.), Psicologia e cardiologia: novas tendências (p. 157-168). Campinas, SP: Ed. Alínea.

Santos, A. F., Santos, L. A., Melo, D. O. \& Alves Júnior, A. (2006). Estresse e estratégias de enfrentamento em pacientes que serão submetidos à cirurgia de colecistectomia. Revista Interação em Psicologia, 10(1), 63-73.

Silva, R. B., \& Boaventura, C. B. F. (2011). Psico-oncologia e Gestalt-terapia: uma comunicação possível e necessária. Revista da Abordagem Gestáltica, 17(1), 37-46.

Sociedade Brasileira de Cardiologia/Sociedade Brasileira de Hipertensão/Sociedade Brasileira de Nefrologia (2010). VI Diretrizes Brasileiras de Hipertensão. Arq Bras Cardiologia, 95(1 supl.1), 1-51.

Yontef, G. M. (1998). Processo, Diálogo e Awareness. São Paulo: Summus.

Juliana de Oliveira Figueiredo - Universidade Federal de Minas Gerais. Rua Bueno Brandão, 579/302 - Santa Tereza. Belo Horizonte/ MG. CEP: 310.10-060.

E-mail: juoliveiraf@gmail.com

Emma Elisa Carneiro Castro - Universidade Federal de Minas Gerais. Rua Francisco Deslandes, 732/101 - Anchieta. Belo Horizonte/MG. CEP: 30.310-530.

E-mail:emma.castro@terra.com.br

Recebido em 06.02.2014

Primeira Decisão Editorial em 23.02.2014

Segunda Decisão Editorial em 21.08.2014

Aceito em 31.01.2015 